\title{
22. PALEOMAGNETIC STUDIES OF SEDIMENTS FROM DSDP SITE 173
}

\author{
Donald F. Heinrichs, School of Oceanography, Oregon State University, Corvallis, Oregon
}

\section{INTRODUCTION}

The natural remanent magnetization (NRM) of 151 sediment samples from DSDP Site 173, Leg 18, was measured. Site 173 is located at $39^{\circ} 57.71^{\prime} \mathrm{N}, 125^{\circ} 27.12^{\prime} \mathrm{W}$ on the Northern California continental slope near the upper reaches of the Delgada Deep-Sea Fan. The initial intent of the study was to obtain the directions of remanent magnetization and, hopefully, determine the magnetic stratigraphy for the entire geologic section, which apparently extends continuously to the Lower Miocene. Sufficient magnetic specimens and a relatively high percent of core recovery enable a tentative magnetic stratigraphy to be proposed for the upper 120 meters of the section which is composed by Pliocene and younger sediments. Both a lower core recovery ratio and fewer samples contribute to less definitive results at depths below 120 meters. Details of the core descriptions, core recovery, and faunal assemblages are not given here but are presented elsewhere in this volume (Chapter 4).

\section{MAGNETIC MEASUREMENTS}

The paleomagnetic measurements were made on a $5 \mathrm{cps}$ fluxgate mangetometer of the type described by Foster (1966). Since the top to bottom orientation of the core is known and the azimuth is arbitrary, in theory, true magnetic inclinations can be determined, but only relative magnetic declinations can be deduced. In practice, it was not possible to calculate reliable inclinations due to instrumental limitations but consistent polarities were determined. The primary restriction in determining inclinations are the small intensities of remanent magnetization.

The minimum total magnetic moment that could reliably be measured on the magnetometer in use was $2.7 \times$ $10^{-6}$ emu. For a standard $10 \mathrm{~cm}^{3}$ sample, the minimum measurable intensity of magnetization is then $2.7 \times 10^{-7}$ $\mathrm{emu} / \mathrm{cm}^{3}$ or approximately $5 \times 10^{-7} \mathrm{emu} / \mathrm{gm}$. The intensity of magnetization of the specimens to a depth of 130 meters in the core was consistently around $1 \times 10^{-6}$ to $5 \times$ $10^{-7} \mathrm{emu} / \mathrm{gm}$. Specimens from depths greater than 130 meters, in general had intensities of magnetization on the order of $5 \times 10^{-6} \mathrm{emu} / \mathrm{gm}$. Thus, the major difficulty in reproducing measurements resulted from rather large "noise" contributions to measured remanence values. Based upon repeated measurements on several selected specimens, inclinations could only be determined to about $\pm 30^{\circ}$ but the sense or polarity of the NRM could be consistently repeated. Rather than present inclinations with large uncertainties, Table 1 lists all magnetic results as polarities only. Specimens with normal polarity are shown as plus signs and reversely magnetized specimens are plotted as a minus sign. Polarity symbols enclosed in parentheses $(+)$ or $(-)$, are from specimens at the minimum resolution of the
TABLE 1

Paleomagnetic Samples From DSDP Site 173 Cores

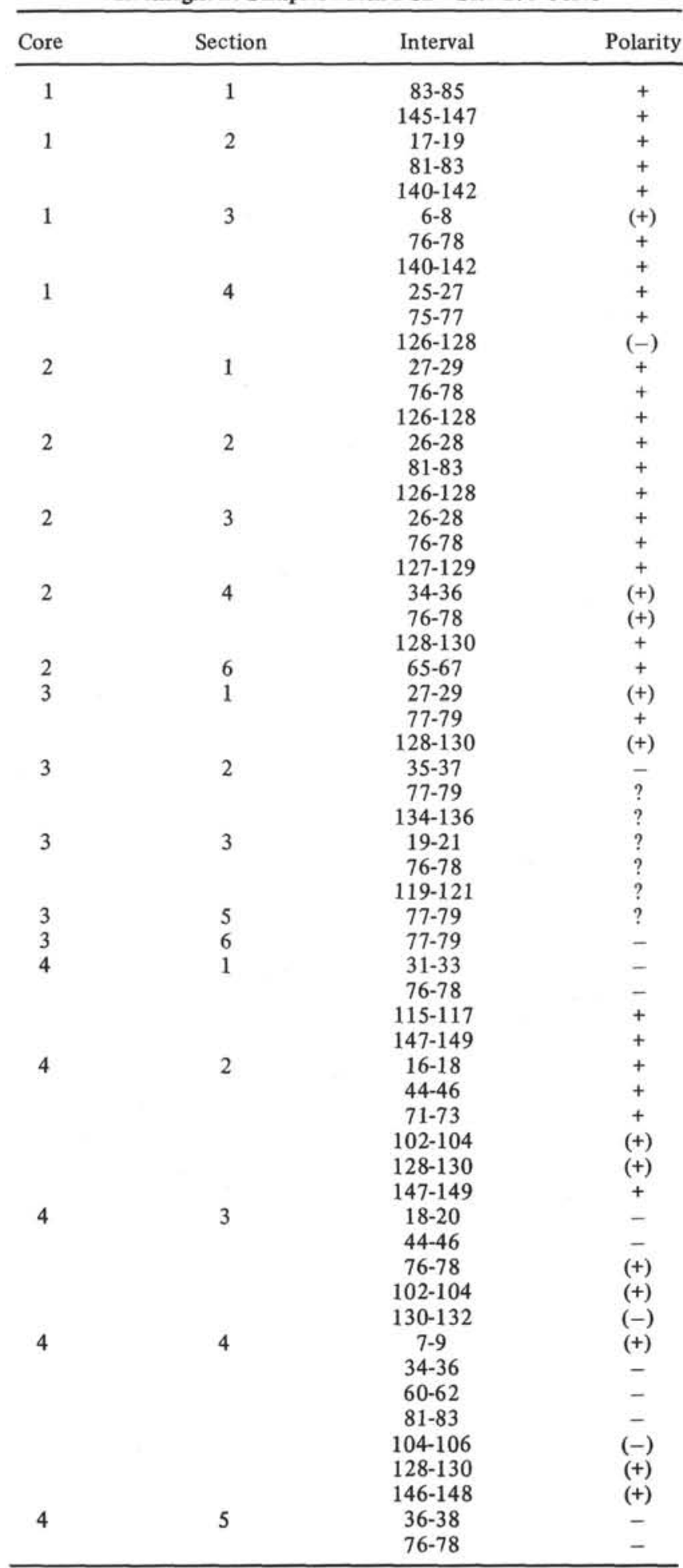


TABLE 1 - Continued

\begin{tabular}{|c|c|c|c|}
\hline Core & Section & Interval & Polarity \\
\hline & & $\begin{array}{l}102-104 \\
130-132\end{array}$ & $\overline{+}$ \\
\hline 5 & 1 & $38-40$ & $(-)$ \\
\hline \multirow[t]{3}{*}{5} & 2 & $19-21$ & - \\
\hline & & $77-79$ & - \\
\hline & & $134-136$ & - \\
\hline \multirow[t]{3}{*}{5} & 3 & 6-8 & - \\
\hline & & $30-32$ & $(-)$ \\
\hline & & $61-63$ & - \\
\hline \multirow[t]{3}{*}{5} & 3 & $76-78$ & - \\
\hline & & $105-107$ & $(-)$ \\
\hline & & $134-136$ & \\
\hline \multirow[t]{5}{*}{5} & 4 & $19-21$ & - \\
\hline & & $44-46$ & + \\
\hline & & $77-79$ & + \\
\hline & & $105-107$ & + \\
\hline & & $135-137$ & - \\
\hline 5 & 5 & $38-40$ & ? \\
\hline 6 & 1 & $147-149$ & - \\
\hline \multirow[t]{3}{*}{6} & 2 & $20-22$ & - \\
\hline & & $61-63$ & - \\
\hline & & $100-102$ & + \\
\hline 7 & 3 & $80-82$ & $(-)$ \\
\hline 7 & 4 & $101-103$ & $(-)$ \\
\hline 8 & 2 & $101-103$ & $(-)$ \\
\hline 8 & 3 & $100-102$ & $(-)$ \\
\hline 8 & 4 & $100-102$ & - \\
\hline 8 & 5 & $100-102$ & - \\
\hline 8 & 6 & $100-102$ & - \\
\hline 9 & 1 & $111-113$ & - \\
\hline 9 & 2 & $100-102$ & + \\
\hline 9 & 3 & $90-92$ & - \\
\hline 9 & 4 & $100-102$ & - \\
\hline 9 & 5 & $100-102$ & - \\
\hline 9 & 6 & $93-95$ & - \\
\hline 10 & 1 & $90-92$ & - \\
\hline 10 & 2 & $97-99$ & - \\
\hline 10 & 3 & $100-102$ & - \\
\hline 10 & 4 & $100-102$ & - \\
\hline 10 & 5 & $100-102$ & - \\
\hline 10 & 6 & $100-102$ & + \\
\hline 11 & 1 & $101-103$ & - \\
\hline 11 & 2 & $101-103$ & - \\
\hline 11 & 3 & $101-103$ & - \\
\hline 11 & 4 & $97-99$ & - \\
\hline 12 & 2 & $99-101$ & + \\
\hline 12 & 5 & $100-102$ & $(-)$ \\
\hline 12 & 6 & $88-90$ & $(-)$ \\
\hline 13 & 1 & $86-88$ & - \\
\hline 13 & 2 & $90-92$ & - \\
\hline 13 & 3 & $100-102$ & - \\
\hline 13 & 4 & $80-82$ & - \\
\hline 13 & 5 & $104-106$ & + \\
\hline 13 & 6 & $74-76$ & $(+)$ \\
\hline 14 & 1 & $100-102$ & - \\
\hline 14 & 2 & $97-99$ & + \\
\hline 14 & 3 & $100-102$ & - \\
\hline 15 & 2 & $104-106$ & - \\
\hline 15 & 3 & $100-102$ & - \\
\hline 15 & 4 & $126-128$ & - \\
\hline 16 & 2 & $103-105$ & + \\
\hline 16 & 3 & $100-102$ & + \\
\hline 17 & 2 & $115-117$ & + \\
\hline 17 & 3 & $78-80$ & $(-)$ \\
\hline 18 & 2 & $100-102$ & + \\
\hline 18 & 3 & $96-98$ & + \\
\hline 18 & 4 & $100-102$ & + \\
\hline 18 & 5 & $100-102$ & + \\
\hline 19 & 2 & $136-138$ & - \\
\hline
\end{tabular}

TABLE 1 - Continued

\begin{tabular}{lccc}
\hline Core & Section & Interval & Polarity \\
\hline 19 & 3 & $120-122$ & - \\
19 & 4 & $115-117$ & + \\
20 & 2 & $81-83$ & + \\
20 & 3 & $100-102$ & + \\
21 & 2 & $38-40$ & + \\
21 & 3 & $109-111$ & - \\
21 & 4 & $92-94$ & - \\
22 & 2 & $115-117$ & - \\
22 & 5 & $58-60$ & - \\
23 & 2 & $61-63$ & - \\
23 & 3 & $117-119$ & - \\
24 & 1 & $135-137$ & - \\
24 & 2 & $64-66$ & - \\
24 & 3 & $100-102$ & - \\
24 & 4 & $100-102$ & - \\
24 & 5 & $121-123$ & - \\
25 & 4 & $19-21$ & - \\
25 & 5 & $123-125$ & $(-)$ \\
26 & 2 & $103-105$ & $(-)$ \\
26 & 4 & $73-75$ & $(-)$ \\
27 & 3 & $127-129$ & $(-)$ \\
28 & 2 & $62-64$ & - \\
28 & 3 & $71-73$ & \\
\hline
\end{tabular}

magnetometer and are considered less reliable. Seven specimens (question marks) were too weakly magnetized to obtain any polarity.

Because of the small intensities of remanent magnetization, the consequent time and effort involved in reducing them, and consistent results from the upper 120 meters of the core, no attempt was made to demagnetize all the specimens. Two specimens, 5-4(19-21) (reverse polarity) and 6-2(100-102) (normal polarity) were demagnetized at 50 and 100 oersteds peak A.F. field. Intensities dropped to about 50 per cent of the initial NRM value without a change in polarity of either sample. It is recognized that this is a minimal test of magnetic stability. The large "noise" contribution to the measured signal of these sample intensities also limits the ability to judge the relative magnetic stability by comparing intensities before and after demagnetization.

The magnetic polarities are shown in Figure 1. For clarity, all specimens from within a given one meter depth are plotted on a single line; the detailed stratigraphy may be obtained from Table 1. Also included is the paleomagnetic time scale of Cox (1969) for the last 3.0 million years and the diatom faunal zone boundaries and ages proposed by Schrader (Chapter 17, this volume). The diatom zone ages are based on the correlation of characteristic faunal assemblages and a proposed magnetic time scale by Burckle (1972). The magnetic time scale used by Burckle differs somewhat from that of Cox. It is basically the same as the time scale presented by Hays and Opdyke (1967) and modified with interpreted values from Opdyke and Foster (1970) and Foster and Opdyke (1970). This author prefers the Cox time scale. See Watkins (1972) for a comprehensive discussion of the various proposed time scales. The application of various time scales does produce different sedimentation rates. 
AGE

(M.Y.)

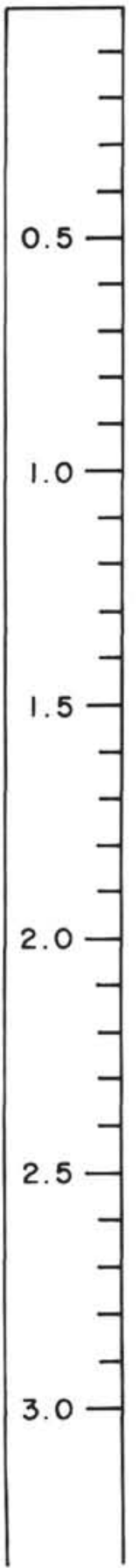

Cox,

(1969)
DSDP 173

(METERS)

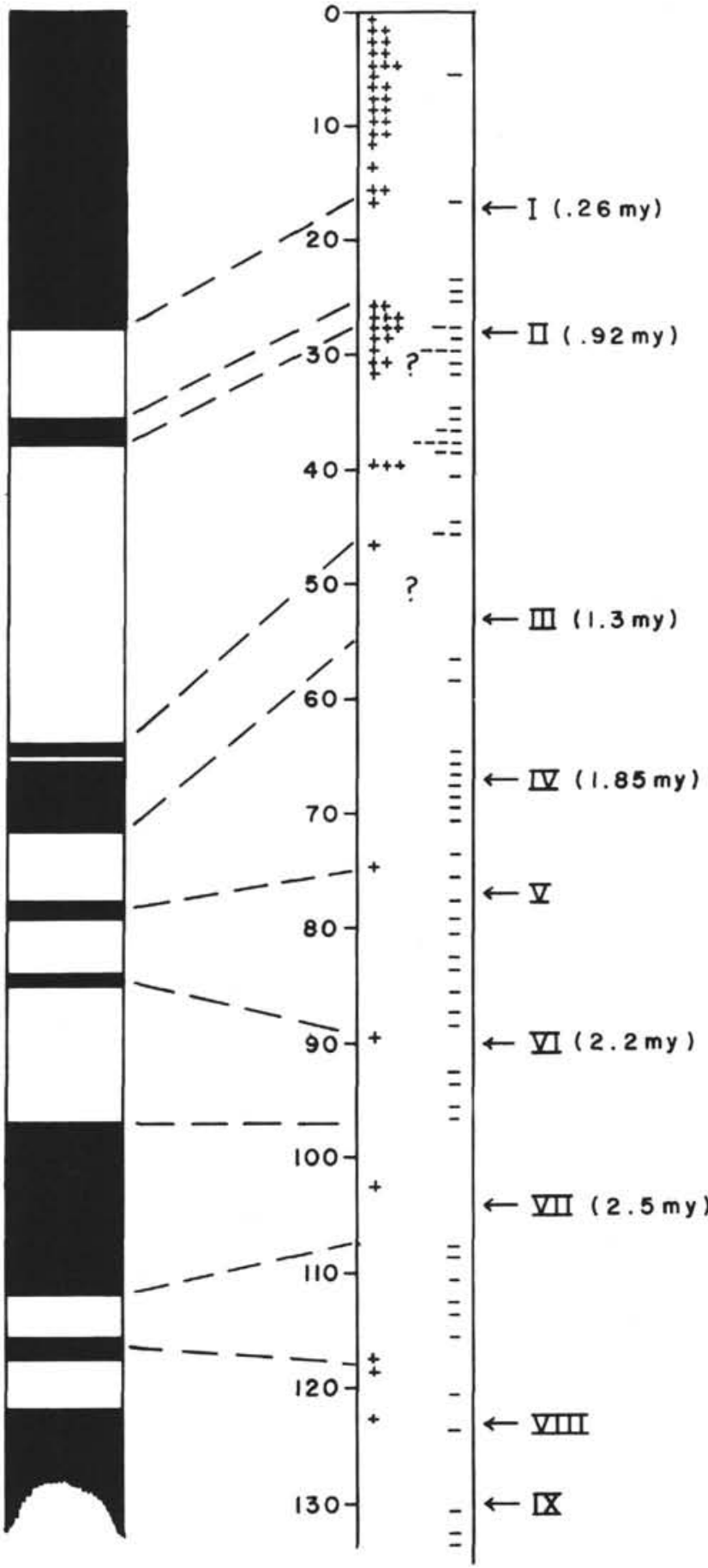

DSDP 173

(METERS)

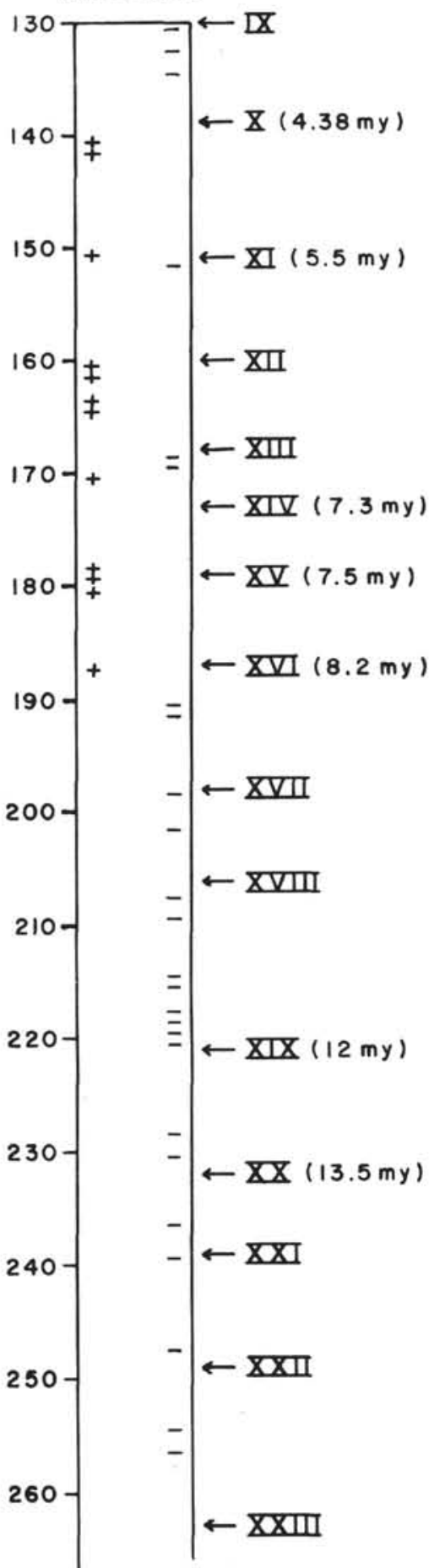

Figure 1. Polarity measurements for DSDP Site 173. Proposed correlations with Cox (1969) time scale are indicated by dashed lines. Roman numerals and ages are diatom zones from Schrader, (this volume).

The proposed correlations between the Cox (1969) magnetic stratigraphy and the polarities measured in the Site 173 specimens are shown in Figure 1. Three normal polarity samples at a depth of 39 meters are unexplained by the proposed correlations. (They also do not fit into the Burckle time scale.) No obvious reasons exist to reject these samples and their incongruity remains unexplained. The major polarity boundaries and centers of events are plotted in Figure 2 vs. depth in the core. For comparison, the estimated ages from the diatom assemblages (Schrader, this volume) are also plotted. The correlations suggest a uniform sedimentation rate of 28.1 meters/my for the last $1.75 \mathrm{my}$ 


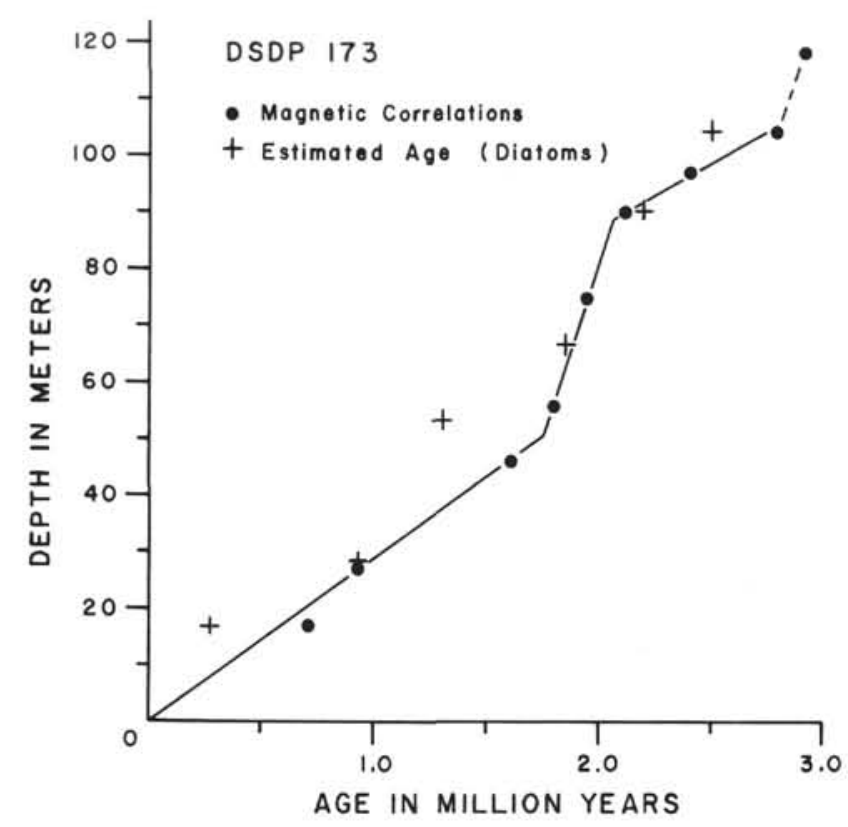

Figure 2. Sedimentation rates based on Cox (1969) time scale. Crosses are based on diatom zones from Schrader (this volume).

with a rapid increase in deposition to 133.3 meters/my for the time interval 1.75 my to 2.05 my. A 28.5 meters/my sedimentation rate is indicated for the time interval 2.05 my to 2.8 my with the suggestion of a second episode of rapid sedimentation prior to $2.8 \mathrm{my}$. The rapid sedimentation rates may be in large part the cause of the small magnetic intensities and consequent difficulties in measuring these samples. The mean sedimentation rate for the entire time interval, 0 to $3.0 \mathrm{my}$, is very similar for the magnetic correlations and diatom zone ages. The fine structure is considerably different, however.

No serious attempt was made to extend the magnetic correlations beyond the 120 meter depth in the core. The polarities of the specimens between 140 meters and 190 meters are dominantly positive. All specimens below 190 meters have a reversed polarity. The intensity of magnetization of these samples are approximately 5 to 10 times as large as the upper sediments. The diatom assemblage ages also suggest deposition rates of less than one-half of the rates in the upper part of the core. The distance between successive specimens is such that entire polarity epochs may not have been sampled. Thus it is possible to "fit" a reversal pattern to these results. Any such correlation, however, would be extremely speculative and was not attempted.

\section{REFERENCES}

Burckle, L. H., 1972. Late Cenozoic planktonic diatom zones from the Eastern Equatorial Pacific. 1-56 (preprint), in print Nova Hedwigia, Beiheft 39, Bremerhaven Symposium, R. Simonsen ed., Lehre 1972.

Cox, A., 1969. Geomagnetic reversals. Science. 163237.

Foster, J. H., 1966. A paleomagnetic spinner magnetometer using a fluxgate gradiometer. Earth Planet. Sci. Lett. 1, 463.

Hays, J. D., and N. D. Opdyke, 1967. Antarctic radiolaria, magnetic reversals and climatic change. Science, 158, 1001.

Opdyke, N. D. and J. H. Foster, 1970. The paleomagnetism of cores from the North Pacific. In Geological Investigations of the North Pacific. J. D. Hays (Ed.). Geol. Soc. Amer. Mem. 126. 83.

Watkins, N. D., 1972. Review of the development of the geomagnetic polarity time scale and discussion of prospects for its finer definition. Bull. Geol. Soc. Am. 83, 551 . 